\title{
La Economía Social y la contratación pública: la herramienta de los contratos reservados
}

\author{
Javier Mendoza Jiménez \\ Cándido Román Cervantes \\ Montserrat Hernández López
}

RESUMEN: Las nuevas leyes de contratación pública suponen una oportunidad para fomentar la participación en la misma de las empresas de Economía Social, con el objetivo de que la contratación contribuya a distintos objetivos sociales y medioambientales. La propia Ley de Contratos del Sector Público establece el fomento de las empresas de Economía Social (además de las PYMES) como una de las prioridades a seguir. Para ello cimienta las posibilidades de introducir criterios sociales y ambientales que están en el corazón de las actividades de la Economía Social y modifica el régimen de los contratos reservados que se consolidan como obligatorios. A pesar de su potencial importancia, este último instrumento ha sido poco estudiado en la bibliografía especializada. En este artículo se presenta un análisis de la evolución de los contratos reservados a nivel estatal en los últimos 10 años, utilizando una muestra de más de 250 procesos de este tipo, que incluye procedimientos de todas las regiones de España y con valores de licitación diversos. Los resultados muestran que los contratos reservados se han utilizado en actividades que van más allá de las tradicionales para el tipo de empresa al que van dirigidos, y que los procedimientos para ello suelen ser más transparentes que los ordinarios. La comparación con una muestra de licitaciones no reservadas expone que la eficacia económica es similar en ambos tipos.

PALABRAS CLAVE: Contratación pública, contratos reservados, Empresas de Inserción, Centros Especiales de Empleo.

CLAVES ECONLIT: B55, H57, L31.

Cómo citar este artículo / How to cite this article: MENDOZA, J., ROMÁN, C. \& HERNÁNDEZ, M. (2019): "La Economía Social y la contratación pública: la herramienta de los contratos reservados", CIRIEC-España, Revista de Economía Pública, Social y Cooperativa, 97, 213-244. DOI: 10.7203/CIRIEC-E.97.14657.

Correspondencia: Javier Mendoza Jiménez, jmendozj@ull.edu.es; Cándido Román Cervantes, croman@ull.edu.es, y Montserrat Hernández López, mhdezl@ull.edu.es, Universidad de La Laguna, Facultad de Economía, Empresa y Turismo. Camino La Hornera, 37. Apartado 456, Código postal 38.200, San Cristóbal de La Laguna, S/C de Tenerife. Escuela de Turismo Iriarte: Paseo Santo Tomás, s/n, 38.400 Puerto de la Cruz, Santa Cruz de Tenerife. 


\section{EXPANDED ABSTRACT}

\section{Social Economy and Public Procurement: the reserved procurements tool}

The European 2020 is a milestone for the change of paradigm of public procurement, which has to become an important part of the sustainable development strategy. The legal evolution from the 2004 to the 2014 package of directives has increased the possibilities to introduce environmental and social consideration., overcoming the traditional system for choosing the most economically efficient offer and linking that selection not only with the price offered but also with criteria related to quality.

This new legal framework opens an opportunity to encourage the participation of the Social Economy organizations in it, aiming to contribute to different social and environmental objectives. In Spain, Law 9/2017 establishes the promotion of the Social Economy (in addition to the SMEs) as one of its priorities. To that end it consolidates the introduction of social and environmental criteria linked with the core activities of the Social Economy.

One of the main legal impulses to broaden the participation of social enterprises into public procurement are the changes that Law 9/2017 has introduced regarding the reserved procurements. This type of procurement differs from regular ones in that participation is limited to two types of organizations: the social integration businesses (Empresas de Inserción) and the Special Employement Centers (Centros Especiales de Empleo) and, among the second ones, only the non-profit entities.

The main novelty created by the Law is the obligation that every public administration has to set a governmental agreement in order to establish the precise amount and sectors that will be reserved for the aforementioned types of entities. This creates an enormous opportunity for these social enterprises, and also offers a huge potential to find new opportunities for collectives at risk of exclusions these organizations normally work with, but also raises a concern about the readiness and preparation of the business to be up to the challenge.

The main aim of this article is to study the evolution and characteristics of the reserved procurements in the period between 2008 and 2018. Despite the potential importance of these instruments, they have been scarcely studied. There is a gap on public procurement research not only regarding the legal characteristics of this type of procurements but especially in relation to their impact. This paper seeks to contribute to the bridging of this research gap using a sample of more than 250 processes extracted from the national and regional procurement platforms in Spain. One of the problems to be faced was the inexistence of the obligation of publication of the procurement in a centralized platform. until the coming into force of the Law 9/2017. 


\section{LA ECONOMIA SOCIAL Y LA CONTRATACION PÚBLICA: LA HERRAMIENTA DE LOS CONTRATOS RESERVADOS}

The methodology employed for the study required the construction of a database with the different procurements found and the identification of diverse characteristics of each of them to favor the analysis. Therefore, the following quantitative and qualitative variables regarding the preparation and evaluation phases have been chosen for the analysis: amount of the contract, type of procedure, category of services, works or supplies (classified according the Common Procurement Vocabulary as regulated by the European Union), and criteria used to award the contract.

The analysis did not focus only on the reserved procurements but also seeks to establish a comparison with the regular procurement to analyze the possible differences between the two types. To do so, two more variables, related to the awarding phase, were considered. The economic efficiency of the contracts, defined as the difference between the procurement budget and the final amount of the contract, and the degree of concurrency, measured as the number of offers presented to each procedure.

To proceed with the comparison, a sample of 100 regular procurements was taken, from similar contractual objects to those of the reserved procurement ample, extracted from the Public Sector Procurement Platform, with the objective of establishing whether or not there are differences between both groups.

The results obtained from the analysis of the reserved procurement sample show that their distribution is heterogenous inside of Spain. Regions like Cataluña, Euskadi and Navarra have advantage both in the of procedures and in accumulated amount over others like La Rioja or Extremadura which are just starting. Moreover, services are the general sector where those contracts are developed, since there is a residual presence of supplies or works. Nevertheless, it is important to note that this kind of procurements have been used in activities beyond the traditional market niche of the social enterprises that might participate in them. Almost 20 types of activities have been identified and most of them have in common the fact that they are intensive on workforce, which is logical due to the social aim of the entities that can benefit from the reserve.

Regarding the procedures used, the reserved procurements are more transparent than he regular ones, with a vast presence of the open procedures. Finally, it is also remarkable that these procedures do not necessarily imply that the criteria used for the awarding are also social or environmental. In comparison with the regular procedures, a similar economic efficacy has been detected, whereas the degree of concurrency is lower in the reserved one, due to the smaller number of businesses that can participate.

This research faces several limitations that also present research opportunities for the future. Firstly, and due to the lack of information, some of the procurements, couldn't be found and therefore were not included in the sample. Secondly, more qualitative variables should be added to the study to esta- 
blish the real impact of the procurements and the obstacles faced by both the public sector and the social entities. Knowing the opinion of the agents involved could point to the difference between regions that rely in the same national law.

Practical conclusion is that, although there is still a long way to go, the reserved procurements have a solid base of example on which the regions in the last positions can stand in order to improve their situation. The study also shows, for the first time, that in economic terms there are not big difference between the reserved procurements and the regular ones, thus supporting the arguments cemented by the new legislation about the possibilities of combining social value without harming the economic efficiency.

KEYWORDS: Public procurement, reserved procurements, social enterprises. 


\section{LA ECONOMIA SOCIAL Y LA CONTRATACION PÚBLICA: LA HERRAMIENTA DE LOS CONTRATOS RESERVADOS}

\section{Introducción' 1}

A través de la contratación pública, los poderes públicos, no solo adquieren los bienes y servicios que necesitan, sino que también realizan una política de intervención en la vida económica, social y política (Gimeno Feliú, 2008:11). Esa doble función coloca a las entidades públicas en una posición privilegiada, para influir en el mercado desde un punto de vista económico, y para poder establecer exigencias que contribuyan a lograr los objetivos sociales y medioambientales establecidos.

Ese poder de influencia parece haber sido desestimado tradicionalmente, desterrando la contratación pública al marco de una mera política económica al establecer la adjudicación de licitaciones públicas mediante la oferta económicamente más ventajosa. El uso de subastas o de criterios relacionados mayoritariamente con el coste produce normalmente un deterioro, entre otros, de la calidad del trabajo, al priorizarse el beneficio económico sobre el bienestar personal. La tendencia de avanzar hacia una contratación pública estratégica se engloba dentro de la contratación pública sostenible o responsable (Oruezabala y Rico, 2012; Walker y Brammer, 2009), y coloca al contrato público como un instrumento al servicio del Estado para alcanzar fines sociales, ambientales o de innovación (Rezzoagli, 2016:5).

Debido al impulso legislativo de principios del siglo XXI, el uso de la contratación pública para alcanzar objetivos sociales está cada vez más extendido. Sin embargo, la información y los métodos para llevarlo a cabo se encuentran a menudo incompletos y son difíciles de definir (McCrudden, 2004: 257). Dentro de esos métodos las cláusulas sociales, y los mercados reservados, o la reserva de mercado son los instrumentos utilizados para establecer la conexión entre la contratación pública y el Estado del Bienestar, debido a que son herramientas innovadoras que pueden dar un nuevo impulso a las políticas de empleo y de inclusión social, y a la inserción laboral de colectivos excluidos del mercado de trabajo, como parte de las políticas sociales de lucha contra la exclusión (Bernete García, 2013:85). Ello no quiere decir que no existan obstáculos para la introducción de este tipo de criterios, que han suscitados numerosas resoluciones de los Tribunales de Recursos Administrativos. Otro de los problemas, que ha sido abordado recientemente por Gutierrez Ponce, Nevado Gil y Pache Durán (2019) es la falta de un sistema de indicadores para medir los efectos de este tipo de criterios.

En el caso de España, la contratación responsable se ha visto reforzada por la nueva Ley de Contratos del Sector Público (en adelante LCSP). En concreto, esta introduce novedades significati-

1.- Este trabajo forma parte del proyecto de investigación "Estudio y redacción de los proyectos de Ley para la implementación de los principios de contratación pública socialmente responsable y la promoción del tercer Sector Social en Canarias", Fundación General de La Universidad de La Laguna y Comisionado de inclusión social y lucha contra la pobreza, 2017, Código: A17120093. 
vas en cuanto a la posibilidad de reservar determinados procedimientos de licitación. Consolida a las Empresas de Inserción como posibles beneficiarias de los contratos reservados y limita a su vez la figura de los Centros Especiales de Empleo (en adelante CEE), exigiendo que estos sean de iniciativa social. De las dos posibilidades que establecen tanto las Directivas de cuarta generación como la LCSP para la reserva de contratos este artículo se centrará en la que actualmente regula la Disposición Adicional Cuarta, esto es, la reserva para los CEE y las Empresas de Inserción?2.

En este artículo se analizará, en primer lugar, el progresivo acercamiento entre la contratación pública y la Economía Social y, seguidamente, las entidades que pueden ser beneficiarias de los contratos reservados. Posteriormente, se comentarán las estrategias que pueden seguirse para establecer una reserva, partiendo de dos variables: el porcentaje de reserva y la limitación sectorial. Seguidamente, usando una muestra de más de 250 procesos de licitación reservada, se expondrán las características de tales licitaciones y se realizará una comparación con los procesos ordinarios. El artículo finaliza con las conclusiones.

\section{El acercamiento de la contratación pública a los principios de la Economía Social}

La contratación pública adolece, dentro del mundo académico, de la atención que sí se ha prestado a la contratación privada (Knight, Harland, y Telgen, 2012), a pesar de los esfuerzos realizados desde los gobiernos para mejorar de los procedimientos implicados (Thai, 2001). Una definición general de la contratación pública la identifica con la adquisición de bienes y servicios por parte de organizaciones del sector público (Uyarra y Flanagan, 2010).

Los principios que rigen la contratación pública, siguiendo a Raymond (2008) son: el valor obtenido, ética, competencia, transparencia y rendición de cuentas. A diferencia de su contrapartida privada, los procedimientos de contratación pública cuentan con una legislación general, que establece un marco, más o menos flexible, en el que se determinan los posibles criterios para valorar las distintas ofertas y los requerimientos que deben cumplir las mismas.

La falta de flexibilidad dentro de la contratación pública ha sido uno de los aspectos más estudiados en la literatura especializada. Dos de las soluciones propuestas ante ese obstáculo han sido, por un lado, la adopción de políticas que lleven a incrementar la competitividad dentro del sector público y, por el otro, aplicar estilos de gestión más cercanos al sector privado dentro de la esfera pública (Hood, 2000), que permitan aprovechar las eficiencias que estas ofrecen (Tadelis, 2012).

2.- La otra posibilidad, que regula la Disposición Adicional Cuadragésima Octava, que amplía el espectro de organizaciones, es de reciente introducción, lo cual limita los casos que pueden tomarse como base del análisis. 


\section{LA ECONOMIA SOCIAL Y LA CONTRATACION PÚBLICA: LA HERRAMIENTA DE LOS CONTRATOS RESERVADOS}

Los últimos cambios legislativos han otorgado una mayor relevancia a la llamada contratación pública responsable. Que tiene que ver con conceptos como la "contratación pública social" (Sáenz, 2018) o "contratación pública socialmente responsable" (Lesmes Zabalegi y Álvarez-de Eulate Bada, 2014). La contratación pública social se relaciona con el desarrollo de la responsabilidad social de las administraciones públicas (Canyelles, 2011; Martínez Fons, 2009), bajo la idea de que, al igual que existe una responsabilidad social corporativa que debe impulsarse desde el sector privado, el sector público también puede (y debe) responsabilizarse de las adquisiciones que realiza, midiendo y controlando los efectos que estas producen La contratación pública responsable se relaciona con el mandato constitucional español que tienen los poderes públicos para el desarrollo de políticas sociales orientadas a la consecución de la igualdad efectiva entre los ciudadanos, a la corrección de situaciones de necesidad y a la implementación de medidas orientadas al pleno empleo (Zúñiga Rial, 2008:66).

Dentro de este modelo, se otorga a la administración pública un papel central para lograr un modelo económico con mayor justicia social. El camino para ello es obtener el mayor valor que el dinero puede comprar en las licitaciones públicas ${ }^{3}$ (Dimitri, 2013). El sector público, en el campo de la contratación, debe ejercer de guía para impulsar la innovación y generar sinergias con los objetivos sociales y ambientales que establezca. En lo relativo a los actores involucrados en las políticas relacionadas con el Estado del Bienestar, la transición hacia métodos más responsables de contratación puede disminuir el poder del mercado y potenciar otra parte del cuarteto de agentes: la Economía Social.

Debido a la magnitud de la contratación pública, que según estimaciones de la OCDE supone alrededor de un $14 \%$ del PIB, se plantea la cuestión de la relación entre el gasto en prestaciones sociales y el gasto en contratación pública, de cara a comprobar si la segunda magnitud podría actuar como "amortiguador" en épocas de crisis donde el gasto social ha tendido a reducirse.

El gráfico 1 recoge la variación interanual, en porcentaje, de ambas magnitudes entre 2004 y 2017, tomando, para la contratación pública, los gastos previstos en los capítulos 2 y 6 de los Presupuestos. La elección de esta fuente para la contratación responde a las limitaciones que presentan otras como los perfiles del contratante, que no suelen incluir todos los procedimientos realizados, o el registro de contratos estatal, que ofrece cifras por lo general muy por debajo del resultado de aplicar las estimaciones de la OCDE y de la UE sobre el peso que supone la contratación pública sobre el PIB.

Para cuantificar la magnitud y evolución del gasto social se ha recurrido al estudio del comportamiento de la partida de gasto en protección social tal y como está definida en el Eurostat ${ }^{4}$, incluye conceptos que se han identificado como claves en el desarrollo del Estado del Bienestar como sanidad (Benavides et al., 2017), pensiones (Espina, 2017), y desempleo (Fernández García y Cabello, 2017).

3.- Best value for money en inglés.

4.- Para más información de los grupos que se consideran dentro de la protección social, consultar: http://ec.europa.eu/eurostat/statisticsexplained/index.php?title=Government_expenditure_on_social_protection\#Expenditure_on_.27social_protection.27. 
El período elegido para el análisis comprende los años de 2004 a 2017 debido a varias razones: es un período lo suficientemente largo de tiempo para permitir comprobar una tendencia en las magnitudes estudiadas, incluyen la etapa previa y posterior a la última crisis económica, y existen datos fiables que pueden extraerse de Eurostat.

\section{Gráfico 1. Variación interanual porcentual de la contratación pública y el gasto social entre 2004 y 2017}

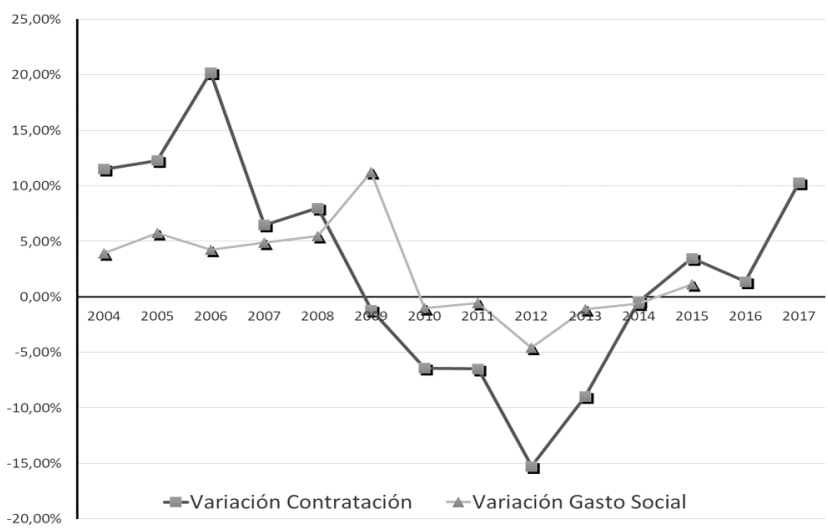

FUENTE: Elaboración propia a partir de los datos de Eurostat y del Ministerio de Hacienda y Función Pública.

Como puede apreciarse, ambas magnitudes han seguido una tendencia similar, e incluso la contratación pública ha sido más volátil que el gasto social cuyo rango de variación oscila entre la variación récord positiva del $11,24 \%$ de 2009 y la negativa de un 4,60 \% en 2012. Precisamente, el año 2012 es el año donde se produjo una mayor reducción de la contratación, que cae un 15,28 \% en ese año, siendo el 2006 el año con la mayor subida registrada, un 20,2\%. Podría concluirse, por lo tanto, que la contratación pública en España no se ha utilizado durante la última crisis como un elemento compensador ante la mala situación de la economía, sino que, al contrario, ha sido una de las partidas que más ha sufrido la misma.

A pesar de las variaciones, la cantidad de dinero que se destina a la adquisición de obras, servicios y suministros representa aún una importante parte del PIB, con potencial para influir en aspectos económicos y también en otros de carácter social y medioambiental. Para ello, es necesario un cambio de mentalidad que considere la contratación pública como una inversión y no solamente como un gasto. En esa búsqueda de una rentabilidad que contribuya a reducir las desigualdades y corregir las ineficiencias de mercado, las nuevas regulaciones parecen haberse acercado a los principios de la Economía Social, dando una mayor importancia al beneficio de la ciudadanía por encima de la 


\section{LA ECONOMIA SOCIAL Y LA CONTRATACION PÚBLICA: LA HERRAMIENTA DE LOS CONTRATOS RESERVADOS}

maximización del beneficio económico, y reforzando el rol de este tipo de entidades dentro del sistema de bienestar.

La Economía Social es un pilar fundamental para el desarrollo de España desde el punto de vista económico y social. Su papel, dentro del esquema de gobernanza se ha ido incrementando paulatinamente, destacando el rol de la Confederación Empresarial Española de la Economía Social (CEPES), quien ha participado activamente en la elaboración de distintas leyes que atañen al sector. La relación entre la Economía Social y la contratación pública ha sido estudiada por autores como García, Marco, y Comeche (2015) quienes destacan el potencial de introducir iniciativas sociales en la contratación pública para la mejora de la calidad de vida de la ciudadanía. Gianfaldoni y Morand (2015) apuntan a la falta de adaptación de las licitaciones a las características de las empresas sociales como uno de los grandes obstáculos La influencia de la Economía Social a la hora de promover una contratación pública socialmente responsable es reconocida, entre otros por Pradini y Sánchez (2007) y Bernete García (2013).

La redacción de la Estrategia Española de la Economía Social 2017-2020 es el último paso que se ha dado dentro de esta colaboración y recoge una serie de ejes, entre los que se menciona la contratación pública, para dar el necesario impulso a este sector. Esta Estrategia reconoce en su exposición de motivos a la Economía Social como "un estandarte fundamental de la recuperación económica y del crecimiento económico sostenible e inclusivo de nuestro país". Su desarrollo contempla 11 ejes y 73 medidas, con el objetivo de desarrollar algunas de las potencialidades detectadas en el sector relacionadas de la economía digital (eje 5), su participación en el diseño e implantación en la Agenda de los Objetivos de Desarrollo Sostenible (eje 11), o su papel para fomentar la igualdad de género y de la inclusión social (eje 9); a paliar algunas de sus debilidades como la necesidad de incremento de visibilidad y difusión (eje 8), el fomento de la participación institucional (eje 6) y la generación de mecanismos de participación innovadores en sectores estratégicos (eje 4).

La Estrategia, de modo amplio, señala los beneficios que tiene el fomento de la Economía Social como soporte de los sistemas de bienestar, y, en su primer eje, que incluye las acciones para el apoyo al empleo y al emprendimiento en el ámbito de la Economía Social, refuerza el papel que distintas medidas de contratación pública pueden tener para ello. En concreto, se hace alusión a la posibilidad de reservar contratos de servicios sociales, culturales y de salud 5 y enfatiza la necesidad de fomentar cláusulas sociales relativas a la contratación, añadiendo a ello la elaboración de un mapa regional con las cláusulas sociales y la reserva de mercado que funcione a modo de banco de datos para el sector público. Se refuerza de esta manera el papel de la contratación pública como fuente de crecimiento integrador, asegurando el uso eficiente de los fondos públicos.

5.- Que se recoge en la disposición adicional cuadragésima octava de la LCSP, que traspone el artículo 77 de la Directiva 24/2014/UE. 


\section{Las entidades de la reserva de mercado: las Empresas de Inserción (EI) y los Centros Especiales de Empleo (CEE)}

De las distintas tipologías de entidades que se encuadran dentro de la Economía Social, los contratos reservados han estado dirigidos fundamentalmente a dos: las Empresas de Inserción y los Centros Especiales de Empleo. Si bien estos tipos de organizaciones tienen menor peso dentro de la economía que otros formatos de empresa, como las cooperativas o las sociedades agrarias de transformación (SAT), no es menos cierto que han sido largamente reconocidas como instrumentos de política social activas. A modo de ejemplo, la exposición de motivos de la Ley 31/2015 de 9 de septiembre, por la que se modifica y actualiza la normativa en materia de autoempleo y se adoptan medidas de fomento y promoción del trabajo autónomo y de la Economía Social destaca que "los datos que señalan un incremento constante del número de trabajadores de las Empresas de Inserción durante los años de mayores dificultades".

\subsection{Las Empresas de Inserción}

Las Empresas de Inserción son agentes de la nueva Economía Social surgidas a impulsos de entidades no lucrativas (Paniagua Zurera, 2013: 189). El espacio que ocupa este tipo de organización empresarial no ha sido claramente definido dentro del contexto de la Economía Social, aunque normalmente se encuadran dentro del grupo de empresas sociales (Chaves Ávila y Monzón Campos, 2008: 45), si bien como tal esta figura está en pocos países de la UE (Monzón Campos y Chaves Ávila, 2012: 32).

El estudio de este tipo de organizaciones es escaso en comparación con otras entidades de la Economía Social como las cooperativas o las mutualidades. Por su novedad metodológica cabe destacar la modelización de su coste para las administraciones públicas que realizaron Retolaza Ávalos y Ramos Fernández (2005), quienes defendían un cambio en el modelo de subvenciones vigente para afrontar los distintos déficits de productividad.

Una buena definición de las Empresas de Inserción (El en adelante) es la propuesta de Álvarez Vega (1999) que resume en pocas palabras las características esenciales de las El calificándolas como iniciativas empresariales que conjugan la lógica empresarial con la lógica de la inserción social. Borzaga (1996) propone una distinción entre empresas "temporales" de inserción (donde el trabajador está un tiempo determinado) y "finalistas" donde se busca que el trabajador permanezca de forma estable en la empresa. Relativo a sus características, Roqueñi et al. (2007) destacan el doble objeto social de las El: el "mercantil" que le viene dado por su actividad de mercado y el "social" relacionado con la inserción laboral. 


\section{LA ECONOMIA SOCIAL Y LA CONTRATACION PÚBLICA: LA HERRAMIENTA DE LOS CONTRATOS RESERVADOS}

Las El representan una "rara avis" dentro de las tipologías empresariales tradicionales. Se trata de una entidad que funciona de manera inusual, puesto que su objetivo último no es contar con los recursos humanos mejor formados para aumentar su productividad -con la lógica excepción del personal de la parte técnica que no está sujeto a esa limitación temporal- sino formar a tales recursos humanos para que posteriormente puedan incorporarse a otras empresas, sociales o no. Usando un símil deportivo, las Empresas de Inserción son una especie de "cantera" donde se forman futuros empleados, que de otra manera tendrían muy complicado acceder al mercado laboral, y menos hacerlo con unas habilidades que les permitieran disfrutar de unas condiciones laborales dignas.

Uno de los referentes para el estudio de este tipo de entidades es el libro en el que López Aranguren (2002) hace un completo repaso de las El en España, cinco años antes de que fueran reguladas a nivel nacional, estudiando en profundidad sus aspectos más relevantes. El estudio de Retolaza, San-Jose, y Araujo (2014) ahonda en los determinantes para su éxito. La investigación sobre las Empresas de Inserción ha tocado aspectos tan diversos como la transparencia en sus cuentas (Marcuello, et al. 2007), su papel como herramienta del emprendimiento social (Melián Navarro y Campos Climent, 2010; Melián Navarro, Campos Climent y Sandrés Palacio, 2011) y la empleabilidad (García Comas, 1999).

Sin embargo, son pocos los estudios de las El a nivel autonómico, entre los que se encuentran los que federaciones regionales como GIZATEA en el País Vasco lanzan periódicamente, el estudio de Rojo Giménez (2000) sobre las Empresas de Inserción en Castilla y León, la guía para la creación de Empresas de Inserción en Canarias (Pradini Olazábal, 2004) y el estudio de Moreno Artiles (1999) donde proponía programas de empleos para grupos desfavorecidos en Las Palmas de Gran Canaria.

El motor de las El, siguiendo el principio de prevalencia de las personas, común a las entidades de la Economía Social, es la creación de empleo. Las Empresas de Inserción se conforman como un instrumento de normalización social y laboral de las personas excluidas (García Gil y García Gil, 2006). Uno de los elementos que forma parte indiscutible, por identificativo de las Empresas de Inserción, es el trabajo de acompañamiento a la persona que está en el proceso de inserción, a lo largo de todo el período que permanece en la empresa (Gil Bartolomé y Ramos Rosario, 2013). El instrumento fundamental con el que trabajan este tipo de organizaciones es el denominado "itinerario de inserción sociolaboral" que va a marcar el proceso de acompañamiento, que puede durar como máximo tres años, durante el cual, en coordinación con los servicios sociales correspondientes, se proporciona al usuario/empleado las herramientas necesarias para que pueda dar el salto al mercado laboral regularizado.

Legislativamente, estas entidades se regulan a nivel estatal por la ley 44/2007 de 13 de diciembre, para la regulación del régimen de las Empresas de Inserción (en adelante LREI) que establece en su artículo 1 que el objetivo del trabajo de las personas en las Empresas de Inserción "es lograr su integración en el mercado de trabajo ordinario, para lo cual, la empresa de inserción contratante facilitará a sus trabajadores el acceso a la formación y a la orientación a través de las acciones y medidas que se establecen en esta Ley". 
La LREI define los colectivos en exclusión que pueden ser trabajadores de las El y el concepto de "itinerario de inserción" referenciado anteriormente. Con respecto a la propia naturaleza de este tipo de organizaciones, no existe límite a la forma empresarial que pueden adoptar, pero se impone la condición, además de estar calificada como tal, de que la entidad debe realizar cualquier actividad económica de producción de bienes y servicios cuyo objeto social tenga como fin la integración y formación sociolaboral de personas en situación de exclusión social como tránsito al empleo ordinario. Las Empresas de Inserción no deben constituirse obligatoriamente sin ánimo de lucro, si bien cuentan con la obligación legislativa de aplicar al menos el $80 \%$ de sus resultados a la mejora de sus estructuras productivas y de inserción.

Según los datos de la Federación Española de Empresas de Inserción, en el año 2017 las 178 Empresas de Inserción constituidas y en funcionamiento contaban en total con más de 6.000 personas empleadas, de las cuales más del $56 \%$ eran personas en inserción. Los ingresos totales de estas empresas fueron de más de 119 millones de euros, con retorno económico de casi 5,2 millones a la administración, lo que supone casi $6.000 €$ por puesto de inserción (FAEDEI, 2018).

Como muestra el cuadro 1, las Empresas de Inserción pueden clasificarse como PYME, puesto que ninguna de las existentes supera los 250 empleados ni un volumen de facturación suficiente para encuadrarlas en la categoría de gran empresa. El sector servicios es predominante entre sus actividades, y las diez mayores organizaciones de este tipo desarrollan sus actividades en este sector.

\section{Cuadro 1. Facturación y empleo de las 10 principales Empresas de Inserción}

\begin{tabular}{|l|l|c|c|c|c|}
\hline $\mathbf{N}^{\mathbf{0}}$ & Nombre empresa & $\begin{array}{c}\text { Facturación } \\
\text { (mill. } \mathbf{\ell})\end{array}$ & Empleo & Lugar & Sector \\
\hline $\mathbf{1}$ & Koopera Servicios Ambientales S. Coop. & 5,89 & 143 & País Vasco & Servicios \\
$\mathbf{2}$ & Ecatar Canarias Slu & 1,50 & 56 & Canarias & Servicios \\
$\mathbf{3}$ & Integrardid S.L. & 1,37 & 80 & Aragon & Servicios \\
$\mathbf{4}$ & Ceislabur S.L.U & 1,10 & 49 & Castilla y León & Servicios \\
$\mathbf{5}$ & Josenea & 1,01 & 35 & Navarra & Servicios \\
$\mathbf{6}$ & Consolida & 0,96 & 36 & Aragón & Servicios \\
$\mathbf{7}$ & Reciplana Recuperacions 2010, SL & 0,95 & 25 & Valencia & Servicios \\
$\mathbf{8}$ & Algo Nuevo S.L. & 0,92 & 55 & Castilla y León & Servicios \\
$\mathbf{9}$ & Inserta S.L. & 0,90 & 46 & Aragón & Servicios \\
$\mathbf{1 0}$ & Fundación Varazdin & 0,81 & 45 & Navarra & Servicios \\
\hline & TOTAL & $\mathbf{1 5 , 4 1}$ & $\mathbf{5 7 0}$ & & \\
\hline
\end{tabular}

FUENTE: Confederación Empresarial Española de la Economía Social (CEPES). 


\section{LA ECONOMIA SOCIAL Y LA CONTRATACION PÚBLICA: LA HERRAMIENTA DE LOS CONTRATOS RESERVADOS}

Las entidades a las que se dirigen los contratos reservados han ido diversificando su actividad paulatinamente hasta salir de los sectores donde tradicionalmente concentraban su actividad. En el caso de las Empresas de Inserción, si bien los servicios son la parte dominante -siguiendo la tendencia general de la economía española- la industria y la construcción tienen un peso relativo importante en cuanto al total de empresas que se dedican a las mismas.

\subsection{Los Centros Especiales de Empleo}

Los Centros Especiales de Empleo (CEE en adelante) son entidades más consolidadas que las Empresas de Inserción, tanto desde el punto de visto histórico, como en lo concerniente a su participación en la reserva de mercado, puesto que la posibilidad de acceder a determinados contratos estaba ya recogida en la Directiva de 2004. Este tipo de organización se define normativamente en el artículo 43 del Real Decreto Legislativo 1/2013 como aquella entidad "cuyo objetivo principal es el de realizar una actividad productiva de bienes 0 de servicios, participando regularmente en las operaciones del mercado, y tienen como finalidad el asegurar un empleo remunerado para las personas con discapacidad".

La Ley de referencia para el colectivo de personas con discapacidad, y por ende para los CEE fue la 13/1982, del 7 de abril, de Integración Social de los Minusválidos, conocida como LISMI. En su artículo 42.2, dicha ley establecía que "la totalidad de la plantilla de los Centros Especiales de Empleo estará constituida por trabajadores minusválidos, sin perjuicio de las plazas en plantilla del personal no minusválido imprescindible para el desarrollo de la actividad". Dicho requisito se ha matizado en el citado RD 1/2013 donde establece el 70 \% como porcentaje mínimo de trabajadores con discapacidad reconocida, sin contar el personal sin discapacidad dedicado a la prestación de servicios de ajuste personal y social, con el que debería contar el centro.

El número de personas con discapacidad de edades entre los 16 y 64 años con discapacidad reconocida en 2015 fue de 1.774.800; cifra que representa el 5,9 \% de la población en edad laboral. De ellos, solo un $34 \%$ son activos, lo que supone una tasa de actividad 44 puntos inferior a la de la población sin discapacidad (Observatorio de las Ocupaciones, 2017). Frente a esa situación de baja actividad y de escasas oportunidades laborales, los CEE han sido considerados por la mayoría de los estudios como una herramienta eficaz de generación de empleo para este colectivo (Comité Español de Representantes de Personas con Discapacidad, 2009; Barea Tejeiro y Monzón Campos, 2008). Tales organizaciones proporcionan alternativas de empleo más seguras que el empleo ordinario, y se considera que tienen una menor demanda personal para las personas con discapacidad en términos de habilidades sociales y laborales (Gómez García, Román Ortega, y Rojo Giménez, 2010).

A pesar de esa buena consideración, durante los últimos años han surgido corrientes críticas que señalan que este tipo de centros contribuye a la segregación de las personas con discapacidad y que, en lugar de constituirse como puente, son un punto de destino para el colectivo de personas 
con discapacidad (Calderón y Calderón, 2012). Conceptualmente, puede existir discusión sobre el encaje de este tipo de organizaciones dentro de la Economía Social, si bien la Ley 3/2011 de Economía Social los enumera dentro de los tipos de entidades de este sector. Sin embargo, el hecho de que los CEE puedan tener ánimo de lucro -ya que legalmente no cuentan con ninguna limitación en este aspecto para su constitución y funcionamiento- hace que, por ejemplo, puedan quedar fuera de los principios que establece la Ley 40/2015 del Tercer Sector de Acción Social, que si incluye muchas de las empresas de la Economía Social.

En cuanto a su peso dentro de la economía española, el Informe Olivenza de 2016 sobre la situación de la discapacidad en España muestra una tendencia creciente de la contratación dentro de los CEE entre 2010 y 2016, que aumentó desde 39.331 a 68.448 personas. Esa cifra representa el 70 $\%$ de los contratos a personas con discapacidad como colectivo especial de contratación en ese último año. La temporalidad es, sin embargo, un problema recurrente dentro de dichas contrataciones y solamente el 8,20\% de los contratos en 2016 eran bonificados, habiéndose reducido dicho porcentaje gradualmente a lo largo del lapso de tiempo considerado y es inferior al que representa la totalidad de la economía que se situó alrededor de un 9 \% según datos del INE de diciembre de 2017.

Según los datos de la Confederación Empresarial Española de la Economía Social (CEPES), en el año 2015, los 10 mayores CEE tenían una facturación conjunta total de 272 millones de $€$ y empleaban a más de 7.100 personas (ver cuadro 2). En cuanto a su especialización, al igual que en el caso anterior de las Empresas de Inserción, los CEE se orientan básicamente hacia el sector servicios con varios nichos de mercado claves como la jardinería, la lavandería y el mantenimiento. Comparando este cuadro con el relativo al de las Empresas de Inserción, se comprueba que los CEE son entidades de mayor dimensión, puesto que entre las 10 mayores existen varias que superan individualmente las cifras en conjunto de las 10 mayores Empresas de Inserción.

Relativo a los contratos reservados, las leyes de contratos de 2007 y 2011 reconocían solo a los Centros Especiales de Empleo y a los programas de empleo protegido como destinatarios potenciales de la reserva, añadiéndose posteriormente las Empresas de Inserción en la Ley 31/2015. Una segunda vía de apoyo público son las distintas subvenciones que están más consolidadas para este tipo de entidades que para otras organizaciones sociales.

El gasto medio por beneficiario en las ayudas concedidas a la integración laboral de personas con discapacidad se ha situado en 2014 en $2.975 €$ (Jiménez y Huete, 2016). Dicho gasto se divide, atendiendo a la información que ofrece el Servicio Público de Empleo Estatal (SEPE) en subvenciones para la financiación parcial de proyectos generadores de empleo para personas con discapacidad, el apoyo al mantenimiento de los puestos de trabajo (incluyendo la bonificación de la cuota empresarial de la seguridad social y la subvención del $50 \%$ del SMI para los puestos a tiempo completo) y la asistencia técnica. 


\section{Cuadro 2. Facturación y empleo de los 10 principales Centros Especiales de Empleo}

\begin{tabular}{|l|l|c|c|c|c|}
\hline $\mathbf{N}^{\circ}$ & Nombre empresa & $\begin{array}{c}\text { Facturación } \\
\text { (mill €) }\end{array}$ & Empleo & Lugar & Sector \\
\hline $\mathbf{1}$ & Ilunion Lavanderias, S.A. & 72,08 & 1.753 & Madrid & Servicios \\
$\mathbf{2}$ & Ilunion Retail y Comercialización & 42,14 & 412 & Madrid & Servicios \\
$\mathbf{3}$ & Ilunion Contac Center & 23,50 & 96 & Madrid & Servicios \\
$\mathbf{4}$ & Ilunion Bugaderia De Catalunya & 23,18 & 593 & Barcelona & Servicios \\
$\mathbf{5}$ & Ilunion CEE Limpieza y Mantenimiento. SA & 21,14 & 2.078 & Madrid & Servicios \\
$\mathbf{6}$ & Mlv & 20,75 & 874 & Valencia & Servicios \\
$\mathbf{7}$ & Ilunion Bpo & 19,62 & 353 & Madrid & Servicios \\
$\mathbf{8}$ & Tasubinsa & 19,00 & 711 & Navarra & Servicios \\
$\mathbf{9}$ & Ilunion Lavanderias De Canarias & 15,96 & 271 & Las Palmas de GC & Servicios \\
$\mathbf{1 0}$ & Ilunion Textil & 15,21 & 37 & Castilla León & Servicios \\
\hline & TOTAL & $\mathbf{2 7 2 , 5 8}$ & $\mathbf{7 . 1 7 8}$ & & \\
\hline
\end{tabular}

FUENTE: Confederación Empresarial Española de la Economía Social (CEPES).

Por su naturaleza, los CEE cumplen una importante labor social y motivan una importante reflexión sobre la compatibilidad de los objetivos sociales y el ánimo de lucro. Debido a que este tipo de entidades combina características de las empresas tradicionales y sociales, han sido objeto de discusiones sobre la compatibilidad del ánimo de lucro y los objetivos sociales. Tales discusiones se han resuelto en la nueva LCSP, excluyendo de la participación en los contratos reservados a aquellos CEE que no sean de iniciativa social. Esta limitación al ánimo de lucro de este tipo de entidades corre el riesgo -en palabras de la presidenta de la Asociación Canaria de Centros Especiales de Empleo- "de crear discapacitados de primera y de segunda clase"6 bajo el argumento de que, dependiendo de la naturaleza de la empresa en la que trabajen, pueden tener más o menos oportunidades laborales. 


\section{Los contratos reservados en España entre 2008 y 2018}

Debido a la inexistencia de datos precisos que permitan conocer no solo la cuantía sino también las características de los contratos reservados, debe recurrirse al estudio separado de varias fuentes. Las dos primeras, relacionadas entre sí, son el Boletín Oficial del Estado y la Plataforma de Contratación del Sector Público, de reciente creación. La tercera es el Foro de la Contratación Pública Responsable, que reúne a muchas de las entidades públicas y privadas que trabajan con el colectivo con discapacidad en España, y que cuenta con información sobre procesos de licitación pública que se han tramitado como contratos reservados, en este caso solamente para Centros Especiales de Empleo. Por último, puede recurrirse también a las Plataformas de Contratación y Perfiles del Contratante regionales y locales disponibles para obtener la información necesaria para el análisis.

A partir ahí, se ha creado un registro en donde los contratos se han clasificado atendiendo a la región, el nivel administrativo, el año de celebración de la licitación y el objeto del contrato (definido en este caso por el CPV) al que hacían referencia. Se han analizado 262 contratos reservados cuyos procesos de licitación se celebraron entre los años 2008 y 2018. Para cada uno de los contratos, se han considerado, además, otras variables como el presupuesto de licitación, el número de licitadores presentados, el importe de adjudicación, el tipo de procedimiento y la existencia o no de criterios sociales y ambientales dentro de los pliegos de cláusulas administrativas y los pliegos técnicos.

La distinta disponibilidad de registros se refleja también en los años a los que corresponden los contratos de la muestra. Los años 2016 y 2017 concentran casi el $45 \%$ del total del volumen licitado en los contratos del estudio. Por lo tanto, existe un claro efecto beneficioso en la transparencia y el acceso a la información del establecimiento de la Plataforma de Contratación del Sector Público a partir de 2016. Lo anterior deber ser encuadrado en la necesaria prudencia que se deriva de usar los perfiles del contratante como una de las fuentes dado que hay que tener en cuenta las limitaciones que supone la posibilidad de que las licitaciones puedan estar alojadas en diversos sitios (Sanmartín Mora, 2017, p.3) como la Plataforma del Estado, bien el Plataformas autonómicas como es el caso de País Vasco, Cataluña o Navarra.

Es de espera que la publicidad de este tipo de contratos, y de todos en general, se incremente debido a lo establecido en el artículo 347 de la LCSP 2017 sobre la obligatoriedad de que todos los perfiles de contratante de todas las entidades del sector público estatal se alojen en dichas plataformas y el establecimiento de que "la publicación de anuncios y otra información relativa a los contratos en los perfiles de contratante surtirá los efectos previstos en la presente Ley cuando los mismos estén alojados en la Plataforma de Contratación del Sector Público o en los servicios de información similares que se establezcan por las Comunidades Autónomas o las Ciudades Autónomas de Ceuta y Melilla". 


\section{LA ECONOMIA SOCIAL Y LA CONTRATACION PÚBLICA: LA HERRAMIENTA DE LOS CONTRATOS RESERVADOS}

En el análisis de la base de datos elaborada partiendo de las fuentes mencionadas se han tenido en cuenta variables de tipo cuantitativo y cualitativo para obtener resultados tanto a escala nacional como, cuando ha sido posible, a escala regional. Los criterios elegidos han sido: volumen y número de contratos, tipo, sector y criterios de adjudicación. A estas categorías, que corresponden a las fases de preparación y valoración de los contratos, se le han añadido otras dos relacionadas con la adjudicación como son: 1) la eficiencia económica, medida a través de la diferencia entre el presupuesto de licitación y el montante económico de la oferta ganadora; 2) la libre competencia, tomando como referencia el número de ofertas que se han presentado a cada licitación.

A este examen se suma una comparativa con una muestra aleatoria de 100 contratos extraídos de la Plataforma de Contratación del Sector Público que se centra en las variables de eficiencia económica y la libre competencia, según se han descrito en el párrafo anterior, con el objetivo de mostrar las diferencias y similitudes entre ambos grupos.

\subsection{Análisis por volumen de licitación y número de contratos}

El primer aspecto analizado hace referencia al volumen y número de licitaciones dividido por regiones e incluyendo también la Administración Central del Estado. Una visión general de dicha distribución, recogida en el cuadro 3, muestra que existen numerosas diferencias tanto en número como en volumen de contratos entre las regiones españolas.

Como puede comprobarse en la información del cuadro 3, Cataluña y Navarra son las dos comunidades con un mayor número de contratos reservados, si bien Euskadi aparece en segunda posición en lo relativo a los importes. En este punto cabe hacer una aclaración para el caso de Navarra: Navarra fue la primera comunidad autónoma con una legislación propia que reconocía la obligación de la reserva de contrato, la Ley Foral 6/2006, de 9 de junio, de Contratos Públicos, y además lo hacía de manera novedosa estableciendo en su artículo 9 que "El importe de los contratos reservados será de un 6 por 100 como mínimo del importe de los contratos adjudicados en el ejercicio presupuestario inmediatamente anterior". 


\section{Cuadro 3. Distribución del volumen de licitaciones y el número de la muestra de contratos reservados en España entre 2008 y 2017}

\begin{tabular}{|l|rrr|}
\hline Región & $\begin{array}{r}\text { Presupuesto de Licitación } \\
\text { (IVA excluido) }\end{array}$ & $N^{0}$ de Contratos & $\begin{array}{r}\text { Media de presupuesto } \\
\text { de licitación }\end{array}$ \\
\hline Andalucía & $2.946 .983,99 €$ & 7 & $420.997,71 €$ \\
Aragón & $11.067 .441,96 €$ & 10 & $1.106 .744,20 €$ \\
Asturias & $2.422 .727,21 €$ & 8 & $302.840,90 €$ \\
Canarias & $142.972,50 €$ & 2 & $71.486,25 €$ \\
Cantabria & $665.428,14 €$ & 5 & $133.085,63 €$ \\
Castilla-La Mancha & $294.807,12 €$ & 2 & $147.403,56 €$ \\
Castilla y León & $1.978 .623,09 €$ & 8 & $247.327,89 €$ \\
Cataluña & $24.844 .460,11 €$ & 80 & $310.555,75 €$ \\
Comunidad Valenciana & $137.593,85 €$ & 4 & $34.398,46 €$ \\
Estatal & $4.739 .624,18 €$ & 18 & $263.312,45 €$ \\
Euskadi & $15.883 .167,99 €$ & 34 & $467.152,00 €$ \\
Extremadura & $4.683 .457,00 €$ & 3 & $1.561 .152,33 €$ \\
Galicia & $1.044 .865,82 €$ & 11 & $94.987,80 €$ \\
Islas Baleares & $1.689 .290,98 €$ & 14 & $120.663,64 €$ \\
La Rioja & $87.931,02 €$ & 1 & $87.931,02 €$ \\
Madrid & $5.144 .639,16 €$ & 21 & $244.982,82 €$ \\
Murcia & $423.896,00 €$ & 4 & $105.974,00 €$ \\
Navarra & $1.782 .441,32 €$ & 30 & $59.414,71 €$ \\
\hline Total & $79.980 .351,44 €$ & 262 & $305.268,52 €$ \\
\hline
\end{tabular}

FUENTE: Elaboración propia a partir de los datos recogidos.

En el caso de Navarra, debido a que dicha legislación lleva en vigor más de 10 años (y que además ha sido recientemente actualizada con la Ley Foral 2/2018 de 13 de abril, de contratos públi$\cos$ ) es de esperar que tanto el número de contratos reservados como la cantidad que suponen sean muy superiores a los que recoge el cuadro. Sin embargo, la búsqueda en las distintas fuentes, incluida la Plataforma de Contratación de Navarra ofrece resultados limitados? ${ }^{7}$.

Teniendo en cuenta dichas limitaciones, cabe destacar la alta cifra que presenta la Comunidad Autónoma de Aragón, que depende en gran medida de una licitación calificada como reservada de más de 7 millones de € que se calificó como contrato de servicios de conservación y mantenimiento

7.- Consultada la administración de esta, razonan que ello puede deberse a que los registros que recoge la misma no incluyen aquellos que los organismos públicos no tienen obligación de publicar, entre ellos los contratos menores que suelen usarse para este procedimiento. 


\section{LA ECONOMIA SOCIAL Y LA CONTRATACION PÚBLICA: LA HERRAMIENTA DE LOS CONTRATOS RESERVADOS}

de parques y zonas verdes y cuya duración era de 4 años. Dicha comunidad, parece seguir, junto con Extremadura, una línea diferente al resto, reservando procedimientos con un presupuesto de licitación superior al millón de euros de media, frente a otras regiones cuya media por contrato es mucho menor.

\subsection{Análisis por tipo de contrato}

El tipo de actividades en el que normalmente trabajan las El y los CEE se ha tenido en cuenta dentro de la LCSP 2017, que incluye un Anexo específico donde se recogen aquellos servicios y suministros (dejando fuera los contratos relativos a obras) que pueden reservarse de acuerdo con la disposición adicional cuarta.

Tal anexo no constituye, sin embargo, legislación básica (según establece la disposición final primera) por lo que no es de obligatoria aplicación para el sector público autonómico y local, que cuenta con libertad para definir que sectores quiere reservar en su caso.

Además, dada la existencia de legislación regional y local, donde se establecen distintos métodos para la reserva de mercado, posibilitándose varias vías o modelos, como se recoge en Mendoza Jiménez, Román Cervantes y Hernández López (2019). Por lo tanto, es de esperar que a partir de la entrada en vigor de dicha LCSP 2017, no se produzcan grandes modificaciones en las licitaciones que se caracterizan como reservadas.

De forma general, los resultados obtenidos muestran la prevalencia de los contratos de servicios sobre cualquier otra categoría. El 97,80\% de los contratos reservados revisados se acomodan en esta categoría mientras que el $1,13 \%$ ha sido calificado como concesiones. Sin embargo, en esta última categoría se ha detectado una incorrecta clasificación, habiendo sido más adecuada su calificación como contratos de servicio debido al objeto que presentan. Ello daría como resultado que casi la totalidad de los registros analizados pertenecen al tipo de servicios, dado que el 0,8\% restante (dos contratos) está clasificado como de suministros.

\subsection{Análisis por sector de actividad}

Las actividades de los CEE y las Empresas de Inserción, dados sus objetivos y los colectivos con los que trabajan, suelen estar centradas en actividades que se denominan "intensivas en mano de obra", que pueden definirse, tomando la ley de contratos de Italia, como aquellas donde la mano de obra supone más del $50 \%$ de los costes. Entonces, es de esperar que, lógicamente, las actividades donde se concentren los contratos reservados sigan el mismo criterio y se concentren en aquellos sectores donde tradicionalmente han trabajado estas entidades. Como se expuso anteriormente, ambas entidades presentan una terciarización en sus actividades, siguiendo la tónica dominante en la economía española. 
Para el análisis de los sectores se ha utilizado el llamado Vocabulario común de contratos públi$\cos$ (CPV) que fue aprobado por el Reglamento (CE) n² 2195/2002 del Parlamento Europeo y del Consejo, de 5 de noviembre de 2002, por el que se aprueba el Vocabulario común de contratos públi$\cos$ (CPV) y modificado posteriormente en 2008 por el Reglamento (CE) No 213/2008 de la Comisión, de 28 de noviembre de 2007.

No es objeto de esta investigación ahondar dentro de la definición y los cambios que el CPV ha sufrido. A modo de resumen, el CPV puede definirse como un sistema de clasificación único aplicable a la contratación pública, con el fin de normalizar las referencias utilizadas por los órganos de contratación y las entidades adjudicadoras para describir el objeto de sus contratos ${ }^{8}$. El CPV se regula mediante un código de hasta nueve dígitos que se estructura en forma de árbol. Los dos primeros dígitos establecen las divisiones. Éstas pueden contener varios grupos (indicados por los tres primeros dígitos), que a su vez se desagregan en clases (definidas por los cuatro primeros dígitos) mientras que los cinco últimos dígitos componen las categorías y sirven para ofrecer información más específica.

Se ha optado aquí por agrupar los distintos contratos reservados al nivel de división, es decir los dos primeros dígitos, basado en dos argumentos: el primero es que este nivel permite identificar de manera clara los tipos de obras y servicios que recoge el objeto del contrato; el segundo es la falta de un criterio definido entre las distintas administraciones públicas a la hora de determinar las clases y categorías de los contratos, lo que puede llevar a que licitaciones con objetos del contrato coincidentes entre distintas administraciones difieran en su CPV. Siguiendo este criterio, el cuadro 4 muestra que los contratos reservados abarcan hasta 18 divisiones distintas, lo cual ofrece un argumento para desmentir la creencia de que las Empresas de Inserción y los CEE se concentran en unos pocos sectores.

Comparando la información del cuadro 4 con lo que expone el Anexo VI de la LCSP 2017, puede comprobarse que, a nivel de división, existe una coincidencia casi total entre ambos. Si bien no recogen exactamente todos los conceptos, dado que la LCSP 2017 introduce la división 18 y la 31, entre otras, y deja fuera las divisiones 15 y 70 , las principales fuentes de contratos reservados sí se encuentran recogidas. 


\section{Cuadro 4. Distribución de los contratos reservados por sectores}

\begin{tabular}{|c|c|c|c|c|}
\hline División & $\begin{array}{l}\mathrm{N}^{\circ} \text { de } \\
\text { contratos }\end{array}$ & $\%$ total & $\begin{array}{l}\text { Importe de } \\
\text { los contratos }\end{array}$ & $\%$ total \\
\hline 15 Alimentos, bebidas, tabaco y productos afines & 3 & $1,18 \%$ & $279.058,80 €$ & $0,35 \%$ \\
\hline 32 Equipos de radio, TV, comunicaciones y anexos & 1 & $0,39 \%$ & $75.604,00 €$ & $0,09 \%$ \\
\hline 34 Equipos de transporte y productos auxiliares & 1 & $0,39 \%$ & $45.454,55 €$ & $0,06 \%$ \\
\hline 39 Mobiliario y productos de limpieza & 1 & $0,39 \%$ & $38.774,00 €$ & $0,05 \%$ \\
\hline 44 Materiales productos auxiliares para la construcción & 1 & $0,39 \%$ & $99.212,00 €$ & $0,12 \%$ \\
\hline 45 Trabajos de construcción & 4 & $1,57 \%$ & $532.540,21 €$ & $0,67 \%$ \\
\hline 50 Servicios de reparación y mantenimiento & 9 & $3,54 \%$ & $2.873 .630,12 €$ & $3,60 \%$ \\
\hline 55 Servicios comerciales al por menor de hostelería y restauración & 5 & $1,97 \%$ & $453.009,48 €$ & $0,57 \%$ \\
\hline 60 Servicios de transporte (excluido el transporte de residuos) & 1 & $0,39 \%$ & $88.192,00 €$ & $0,11 \%$ \\
\hline $\begin{array}{l}63 \text { Servicios de transporte complementarios y auxiliares; } \\
\text { servicios de agencias de viajes }\end{array}$ & 1 & $0,39 \%$ & $35.400,72 €$ & $0,04 \%$ \\
\hline 64 Servicios de correos y telecomunicaciones & 6 & $2,36 \%$ & $751.828,22 €$ & $0,94 \%$ \\
\hline 70 Servicios inmobiliarios & 1 & $0,39 \%$ & $102.240,00 €$ & $0,13 \%$ \\
\hline 71 Servicios de arquitectura, construcción, ingeniería e inspección & 4 & $1,57 \%$ & $1.634 .820,30 €$ & $2,05 \%$ \\
\hline 72 Servicios ti: consultoría, desarrollo de software, internet y apoyo & 4 & $1,57 \%$ & $516.907,91 €$ & $0,65 \%$ \\
\hline 73 Servicios de investigación y desarrollo, y de consultoría conexos & 3 & $1,18 \%$ & $272.775,16 €$ & $0,34 \%$ \\
\hline $\begin{array}{l}75 \text { Servicios de administración pública, defensa y servicios de } \\
\text { seguridad social }\end{array}$ & 1 & $0,39 \%$ & $102.600,00 €$ & $0,13 \%$ \\
\hline 77 Servicios agrícolas, forestales, hortícolas, acuícolas y apícolas & 54 & $21,26 \%$ & $24.691 .222,56 €$ & $30,94 \%$ \\
\hline $\begin{array}{l}79 \text { Servicios a empresas: legislación, mercadotecnia, asesoría, } \\
\text { selección de personal, imprenta y seguridad }\end{array}$ & 29 & $11,42 \%$ & $13.118 .704,21 €$ & $16,44 \%$ \\
\hline 85 Servicios de salud y asistencia social & 11 & $4,33 \%$ & $2.121 .319,55 €$ & $2,66 \%$ \\
\hline 90 Servicios de alcantarillado, basura, limpieza y medio ambiente & 86 & $33,86 \%$ & $25.391 .420,85 €$ & $31,82 \%$ \\
\hline 92 Servicios de esparcimiento, culturales y deportivos & 10 & $3,94 \%$ & $2.024 .529,11 €$ & $2,54 \%$ \\
\hline 98 Otros servicios comunitarios, sociales o personales & 18 & $7,09 \%$ & $4.549 .717,02 €$ & $5,70 \%$ \\
\hline
\end{tabular}

FUENTE: Elaboración propia a partir de los datos de la muestra.

Tomando como referencia las cinco divisiones que aglutinan el mayor número de contratos y la mayor cantidad licitada, se observa que la división 77, de Servicios Agrícolas, Forestales, Hortícolas, Acuícolas y Apícolas y la división 90, de Servicios de Alcantarillado, Basura, Limpieza y Medio Ambiente concentran en conjunto más del $55 \%$ de los registros y casi el $65 \%$ de los volúmenes licitados. Ello se debe a que dentro de la división 77 se encuentran los servicios de mantenimientos de parques, jardines y zonas verdes análogas, que han sido objeto de numerosos contratos reservados, mientras que la división 90 aglutina otros sectores tradicionales para las empresas beneficiarias de la reserva como son la limpieza y la gestión de residuos. 
Además de lo anterior, destacan los servicios a empresas (división 79), donde se incluyen objetos tan dispares como la digitalización de documentos y los servicios de recepción, los servicios comunitarios (división 98), donde se encuadran servicios de lavado y planchado, de portería y similares, y los servicios de reparación y mantenimiento (división 50) dedicada a los servicios de mantenimiento vial. Sorprende la poca incidencia de la división 85 , de servicios de salud y asistencia social, con apenas 11 contratos y unos 2 millones de euros de volumen, dado que es uno de los nichos de mercado de las Empresas de Inserción. El hecho de que, a nivel estatal, la reserva de mercado para este tipo de entidades esté regulada solo desde finales de 2015, podría explicar este resultado.

\subsection{Análisis según los criterios de adjudicación}

Otro de los factores que puede arrojar luz sobre este, hasta el momento, poco explorado campo, es comprobar qué factores de adjudicación se han usado para licitar los mismos. Teniendo en cuenta que se encuadran dentro de una contratación más social, sería de esperar que el criterio "precio" tuviera un menor impacto que en las licitaciones generales, y que aquellos casos, donde éste fuera el único criterio de adjudicación, fueran residuales. Los datos recogidos demuestran que a pesar de lo que pudiera esperarse, en uno de cada cinco contratos el precio es el único criterio que se ha valorado para la adjudicación, siguiendo la lógica de que la adjudicataria fuera aquella empresa que presentara la oferta más baja. Ello puede justificarse debido al tipo de actividades para los que se reserva el contrato, donde algunos de ellos, como la digitalización de documentos, los servicios administrativos, etc. están bien definidos y pueden ser objeto de escasa innovación en su desempeño. Igualmente, estos datos vienen a demostrar que la reserva de mercado no está reñida con la eficiencia económica, como se verá en el apartado siguiente con más detalle, y que una licitación de este carácter no supone automáticamente la desaparición (o minimización) del precio como factor decisivo para la adjudicación.

Un segundo factor dentro de la categoría de criterios de adjudicación es la introducción, o no, de criterios sociales y medioambientales como parte de los pliegos de cláusulas administrativas y criterios técnicos. Al igual que con el factor precio, la lógica indicaría que los criterios sociales y ambientales estuvieran presentes dentro de las licitaciones, siguiendo la línea de una contratación más responsable. Sin embargo, parece existir una cierta incompatibilidad entre los contratos reservados y los criterios sociales y ambientales, dado que solamente un $21,56 \%$ de los mismos incluyen este tipo de criterios. Esto puede tener justificación, puesto que el tipo de empresa para el que se reserva el contrato ya asegura, o debería, el cumplimiento de una serie de criterios como el trabajo con colectivos de difícil inserción, unas condiciones laborales dignas, etc. Además, al haberse celebrado muchos contratos anteriormente a la entrada en vigor de la Directiva 2014, el respaldo legal de la cláusulas sociales y ambientales no estaba tan consolidado, lo que puede haber repercutido en su bajo uso. 


\section{LA ECONOMIA SOCIAL Y LA CONTRATACION PÚBLICA: LA HERRAMIENTA DE LOS CONTRATOS RESERVADOS}

\subsection{Eficiencia económica}

Los contratos reservados suponen un beneficio social al emplear fundamentalmente a personas en exclusión o riesgo de padecerla, lo cual puede tener un efecto multiplicador. Tal efecto no es incompatible, aunque existan manifestaciones al contrario que se acogen a la limitación de la libre competencia como un obstáculo insalvable, con la eficiencia económica de este instrumento.

En este artículo, la eficiencia económica se ha medido usando un factor común a todo tipo de contratos: la diferencia entre el presupuesto de licitación y el importe de adjudicación. Para ello se han tomado, dentro de la muestra de este estudio, los datos correspondientes a aquellos procedimientos en los que se dispone la cantidad por la que finalmente se ha adjudicado la licitación. ${ }^{9}$

Los resultados muestran que la diferencia entre el total de presupuesto de licitación y el importe de adjudicación alcanzó un 10,23\%. Estos datos suponen un espaldarazo al uso de este instrumento también desde el punto de vista económico, puesto que demuestran que la búsqueda de una mayor utilidad social no comporta necesariamente un aumento de los costes económicos previstos. Se apoya, de esta manera, el argumento de que la eficiencia social no está reñida con los parámetros que se usan frecuentemente para medir la eficiencia económica.

\subsection{La competencia en los procedimientos reservados}

Uno de los argumentos que más se ha esgrimido contra a la realización de contratos reservados es la limitación de la libre competencia que suponen. Es cierto que, restringiendo la posibilidad de participación a los CEE y las Empresas de Inserción, la enorme mayoría del tejido productivo queda fuera de este tipo de licitaciones, lo cual ha provocado reacciones en forma de recursos a los pliegos de cláusulas administrativas particulares. Sin embargo, existe una clara justificación social detrás de esta tipología de licitación que reconoce la LCSP mediante la excepción a la no discriminación por tipo de empresa que recoge en su artículo 132.

Para medir el grado de competencia, se ha usado como variable el número de empresas que han presentado ofertas en cada licitación. Los casos donde se presenta una única oferta no alcanzan el $50 \%$, aunque sí suponen la mayoría. En más de un $25 \%$ de las licitaciones se han presentado tres o más ofertas. Por lo tanto, no puede afirmarse que los contratos reservados se constituyan en una suerte de contrato de adjudicación directa para los CEE y las Empresas de Inserción, puesto que como ponen de manifiesto los datos, en una mayoría de los casos analizados existen al menos dos ofertas que compiten entre sí.

9.- (que provienen en su mayoría de la Plataforma de Contratación del Sector Público, dado que las otras fuentes, con la honrosa excepción de algunas plataformas regionales como la de Cataluña, no cuentan con el necesario seguimiento de todas las fases de la licitación y suelen limitarse al anuncio de licitación. 


\section{Comparativa con contratos no reservados}

A lo largo de este artículo se han examinado distintos aspectos de los contratos reservados y extraído una serie de conclusiones sobre su naturaleza en términos de tipología, sectores de actividad, eficiencia económica y afectación a la libre competencia. Para finalizar con dicho examen, se propone a continuación una comparación con los contratos no reservados para comprobar las similitudes y diferencias entre los dos grupos.

Para comparar los procedimientos usados para ambos casos, divididos según la clasificación del Ministerio de Hacienda y Función Pública, se han tomado los datos de los contratos realizados por las entidades del sector público estatal, las comunidades autónomas y los entes locales, y se ha calculado el porcentaje de contratos por cada procedimiento de adjudicación y los volúmenes adjudicados.

Como se observa en el gráfico 2, la mayoría de los contratos han sido licitados por un procedimiento negociado con o sin publicidad, lo cual puede tener efectos perniciosos dentro de la transparencia debido a que puede limitar la información a los licitadores potenciales y disminuir con ello el número de ofertas presentadas. Según el criterio de volumen, se observa que casi tres cuartas partes de las licitaciones se ha realizado mediante procedimiento abierto, lo que sigue una línea más coherente con el principio de transparencia que marcan las sucesivas leyes de contratación pública.

\section{Gráfico 2. Distribución del número de licitaciones públicas y volúmenes licitados en España en 2016 atendiendo al tipo de procedimiento}

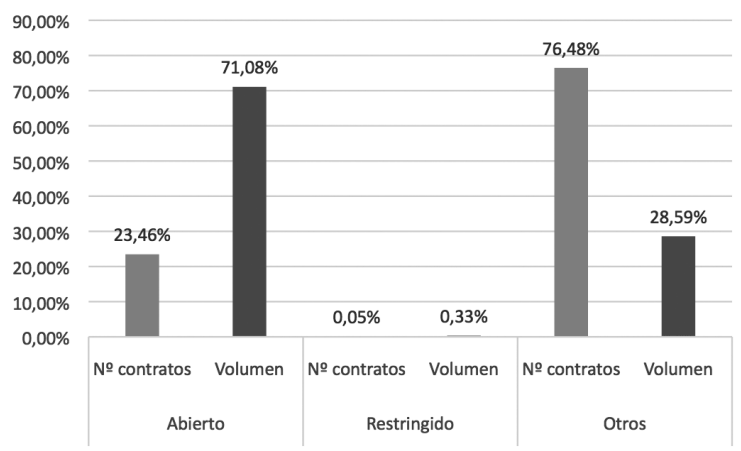

"Nota: El procedimiento "otros", siguiendo la clasificación del Ministerio de Hacienda y Función Pública, incluye los contratos adjudicados por procedimiento negociado, diálogo competitivo, directo y aquellos en los que no consta el mismo.

FUENTE: Elaboración propia a partir de los datos recogidos. 


\section{LA ECONOMIA SOCIAL Y LA CONTRATACION PÚBLICA: LA HERRAMIENTA DE LOS CONTRATOS RESERVADOS}

La comparación con los contratos reservados expone que, tanto en número de procedimientos como en volumen licitado, la utilización del procedimiento abierto es muy superior en ambos casos a la de las licitaciones ordinarias, a pesar de que dado el número más reducido de empresas podría esperarse una mayor incidencia, entre otros, del procedimiento negociado sin publicidad por razón de cuantía que, sin embargo, es prácticamente residual (ver cuadro 5).

\section{Cuadro 5. Comparación por tipo de procedimiento}

\begin{tabular}{|l|cc|cc|}
\hline & \multicolumn{2}{|c|}{ Número de contratos } & \multicolumn{2}{c|}{ Volumen de licitación } \\
\hline Procedimiento & $\%$ General & \% Reservado & \% General & $\%$ Reservado \\
\hline Abierto & $23,46 \%$ & $90,80 \%$ & $71,08 \%$ & $96,68 \%$ \\
Otros & $76,48 \%$ & $6,13 \%$ & $28,59 \%$ & $0,74 \%$ \\
Restringido & $0,05 \%$ & $0,06 \%$ & $0,33 \%$ & $0,38 \%$ \\
\hline
\end{tabular}

FUENTE: Elaboración propia a partir de los datos recogidos.

Una segunda área de comparación tiene que ver con la eficiencia económica y la libre competencia. Para ello, dado que no se han encontrado datos concretos sobre el número de ofertas presentadas para las licitaciones y sobre la baja económica que presentaba la oferta ganadora, se ha recurrido a una muestra de 100 contratos, extraída de la Plataforma de Contratación del Sector Público, que cumplían con tres condiciones: sus CPVs eran similares a aquellos de los contratos reservados examinados, existían datos de todas las fases de la licitación que han pasado, y estaban resueltos dentro del año 2017.

En lo relativo a la eficiencia económica, para la muestra considerada, la diferencia entre el presupuesto de licitación y el importe de adjudicación es ligeramente mayor en los contratos reservados $(10,23 \%)$ que en los contratos generales $(10,11 \%)$. Esta diferencia puede ser un hecho sorprendente y ofrece un interesante punto de reflexión sobre la compatibilidad entre la reserva de mercado y el ahorro para las administraciones públicas, también por la vía de una menor oferta económica. En este punto cabe mencionar las subvenciones que reciben los CEE y las Empresas de Inserción, las cuales permiten cubrir una serie de costes laborales. Por otro lado, el principio de prevalencia de las personas da lugar a que las ofertas puedan ajustarse más para asegurar la consecución de un contrato que genere actividad que para obtener un simple beneficio económico.

Por último, en lo que afecta a la libre competencia, medida a través del número de ofertas presentadas, es de esperar que la media de ofertas que se presenten a cada licitación sea mayor en los contratos generales, dado que no existe restricción por tipo de entidad. Como puede observarse en el cuadro 6 dicha condición se cumple y la media de ofertas presentadas es casi el doble en el caso de los contratos generales. 
Este dato se refuerza atendiendo a la distribución porcentual, que muestra cómo en el caso de los contratos ordinarios, el grupo más numeroso es el de 3 o más ofertas, repartiéndose equitativamente las demás categorías. Sorprende, sin embargo, que la mitad de las licitaciones generales examinadas (el $58 \%$, concretamente) presenten tres o menos ofertas, ya que pone en entredicho si realmente existe una competencia abierta en dichas licitaciones.

\section{Cuadro 6. Comparación por número de ofertas presentadas}

\begin{tabular}{|lcc|}
\hline$N^{0}$ de ofertas & $\begin{array}{c}\text { Muestra de } \\
\text { contratos reservados }\end{array}$ & $\begin{array}{c}\text { Muestra } \\
\text { contratos generales }\end{array}$ \\
\hline 1 & $44,62 \%$ & $21,00 \%$ \\
2 & $29,23 \%$ & $19,00 \%$ \\
3 & $9,23 \%$ & $18,00 \%$ \\
$>3$ & $16,92 \%$ & $42,00 \%$ \\
\hline Media & 2,15 & 3,96 \\
\hline
\end{tabular}

FUENTE: Elaboración propia a partir de los datos de la muestra.

El propio Ministerio de Hacienda y Función Pública recoge esta preocupación al incluir entre los indicadores de competencia para elaborar el informe a que se refiere el artículo 328.4 de la Ley 9/2017, de 8 de noviembre, de contratos del sector público, el siguiente:

"b) Sobre el dato anterior, número total de contratos en los que sólo se recibió una oferta" (Ministerio de Hacienda y Función Pública, 2018: 93).

La comparativa realizada muestra que los contratos reservados, si bien presentan un índice menor en cuanto al número de ofertas para cada licitación -que está condicionado por el número de empresas que pueden presentarse- superan a los contratos generales en cuestiones de transparencia, con un mayor uso y volumen licitado a través de los procedimientos abiertos, e incluso de eficiencia económica, presentando mayores bajas con respecto al presupuesto de licitación. Por lo tanto, este análisis puede considerarse una muestra de la compatibilidad de la eficiencia social y de la eficiencia económica. 


\section{LA ECONOMIA SOCIAL Y LA CONTRATACION PÚBLICA: LA HERRAMIENTA DE LOS CONTRATOS RESERVADOS}

\section{Conclusión}

La progresiva evolución de la legislación de contratación la ha consolidado como otro de los impulsores de la Economía Social desde el sector público, que ha venido a sumarse a las formas más tradicionales como las subvenciones y los convenios. No sólo se han introducido aspectos novedosos relacionados con la filosofía de las entidades que forman la Economía Social, como los criterios sociales que ponen a la persona por encima del puro beneficio empresarial y el control de que todas las ofertas aseguren el cumplimiento de la legislación social y ambiental, sino que también se ha garantizado que las dificultades a las que se enfrentan las empresas sociales al acceder al mercado (según establece el considerando 36 de la Directiva 2014/24/UE), se vean minoradas con medidas que las favorecen.

Dentro de estas medidas, los contratos reservados han tenido un crecimiento sostenido, a medida que la legislación ha ido afianzando su validez y extendiendo esta figura a otro tipo de entidades como las Empresas de Inserción y otras organizaciones de Economía Social. Este tipo de licitaciones son una herramienta que puede contribuir a las nuevas políticas activas de empleo, ya que supone que los itinerarios de inserción se realicen dentro de una actividad real.

El análisis realizado en este artículo demuestra que a través de los contratos reservados puede lograrse la diversificación de las actividades de ciertas entidades sociales y al mismo tiempo la consolidación de sectores tradicionales. Las cifras que ofrece el Informe Relativo a la Contratación Pública en España 2017 del Ministerio de Hacienda y Función Pública, muestran que los procedimientos reservados representan el $2,72 \%$ del total de las licitaciones realizadas, pero no dicen nada acerca de su valor, siendo necesaria una mejora de las fuentes de información, que debería alcanzar a toda la contratación pública.

La comparación con las licitaciones ordinarias muestra que es posible la combinación de beneficio social y económico, toda vez que la reserva para estas entidades sociales no conlleva que las licitaciones se adjudiquen a un mayor precio. Este argumento viene a reforzar la línea seguida por las directivas de cuarta generación y la reciente Ley de contratos para lograr que la contratación pública se constituya en uno de los pilares para afianzar las políticas sociales. Ello se hace, además, a través de procedimientos que son, por lo general, más transparentes.

Las Empresas de Inserción y los Centros Especiales de Empleo todavía representan una parte pequeña, pero no desdeñable del peso de la Economía Social en cuanto a volumen de negocio y empleo generado. Las nuevas posibilidades que ofrece la legislación en el ámbito de la contratación pueden contribuir a aumentar su participación en la misma, para lo que es necesario una mayor profesionalización que les ayude a estar preparados para ese incremento. 
A pesar de estar recogidos en la legislación desde hace más de 10 años, el impacto de los procedimientos reservados en España es todavía escaso y no se distribuye uniformemente en todo el territorio. Ello apunta a que existen una serie de obstáculos, no relacionados con la normativa, que impiden una expansión todavía más rápida de este tipo de instrumentos. El estudio de tales obstáculos puede contribuir aún más al conocimiento y la expansión de estos procedimientos de contratación pública y apoyar las acciones propias del Estado del Bienestar, beneficiando la contratación de personas que pertenecen a colectivos con especiales dificultades para acceder al mercado de trabajo ordinario.

\section{Referencias bibliográficas}

ÁLVAREZ VEGA, M.I. (1999): "Las Empresas de Inserción social como nueva forma de organización empresarial. Especial referencia a su régimen jurídico", CIRIEC-España, Revista de Economía Pública, Social y Cooperativa, 31, 47-84.

ARTILES, F.J.M. (1999): "Programas de empleo en grupos desfavorecidos: una experiencia en Las Palmas de Gran Canaria", Papeles Del Psicólogo, 72, 4.

BAREA TEJEIRO, J. \& MONZÓN CAMPOS, J.L. (2008): "Economía Social e inserción laboral de las personas con discapacidad en el País Vasco", Informes 2008, 184.

BARTOLOMÉ, M.E.G. \& ROSARIO, N.R. (2013): "Las Empresas de Inserción en la Economía Social y solidaria: perspectivas y propuestas desde FAEDEI/Insertion companies in social and solidarity economy: perspectives and proposal from FAEDEl", Cuadernos de Trabajo Social, 26(1), 43. DOl: http://dx.doi.org/10.5209/rev_CUTS.2013.v26.n1.40755.

BENAVIDES, F.G., DELCLÓS, J. \& SERRA, C. (2018): "Estado de bienestar y salud pública: el papel de la salud laboral", Gaceta Sanitaria, 32, 377-380. DOI: https://doi.org/10.1016/j.gaceta.2017.07.007.

BERNETE GARCÍA, J. (2013): "Cláusulas sociales en la contratación pública: Nuevos instrumentos para el fomento del empleo a nivel local", Cuadernos de Trabajo. Social, 26(1), 85-94. https://doi.org/10.5209/rev_CUTS.2013.v26.n1.40691.

BORZAGA, C. (1996): "Paro de larga duración e iniciativas de inserción por la economía". En: Inserción Social por el trabajo. Una visión internacional, Barcelona: Ed. CIES (Centro de Iniciativas de la Economía Social), 39-56.

CANYELLES, J.M. (2011): "Responsabilidad social de las administraciones públicas", Revista de Contabilidad y Dirección, 13(7). 


\section{LA ECONOMIA SOCIAL Y LA CONTRATACION PÚBLICA: LA HERRAMIENTA DE LOS CONTRATOS RESERVADOS}

CALDERÓN MILÁN, M.J. \& CALDERÓN MILÁN, B. (2012): "Los Centros Especiales de Empleo como mecanismo de tránsito hacia el mercado de trabajo ordinario", CIRIEC-España, Revista de Economía Pública, Social y Cooperativa, 75, 222-249.

CHAVES ÁVILA, R. \& MONZÓN CAMPOS, JL (2008): "Panorama de la investigación en Economía Social", Estudios de Economía Aplicada, 26 (1), 29-55. Disponible en: http://www.redalyc.org/articulo.oa?id=30114081002.

COMAS, C.G. (1999): "Empleabilidad y Empresas de Inserción”, Documentación Social, 117, 309-320.

CERMI (2009): El impacto de la crisis económica en las personas con discapacidad y sus familias, Vol. 43, Comité Español de Representantes de Personas con Discapacidad.

DIMITRI, N. (2013): "Best value for money in procurement." Journal of Public Procurement, 13(2), 149-175.

ESPINA, Á. (2017): "La reforma de las pensiones y el Estado de Bienestar: un marco conceptual", Boletín ICE, 3085.

FAEDEI (2018): Memoria Social Empresas de Inserción 2017, Federación de Asociaciones Empresariales de Empresas de Inserción (FAEDEI). Disponible en: http://www.faedei.org/images/docs/documento70.pdf.

FERNÁNDEZ GARCÍA, T. \& ANDRÉS CABELLO, S. (2017): "El estado de bienestar en España en un escenario de crisis sistémica", Sistema: Revista de ciencias sociales, 245, 3-16.

GARCÍA, M.S., MARCO, J.N. \& COMECHE, R.C. (2015): "Incorporación de valor social a la contratación pública en España: Situación y perspectivas", Revista de Estudios de La Administración Local y Autonómica.

GIANFALDONI, P. \& MORAND, P. (2015): "Incentives, Procurement and Regulation of Work Integration Social Enterprises in France: Old ideas for new firms?", Annals of Public and Cooperative Economics, 86(2), 199-219.

GIL, M.B.G. \& GIL, M.B.G. (2006): Los instrumentos jurídicos de la política de empleo, Thomson/Aranzadi.

GIMÉNEZ, C.R. (2000): "Empresas de Inserción en Castilla y León", CIRIEC-España, Revista de Economía Pública, Social y Cooperativa, 36, 97-115.

GIMENO FELIÚ, J.M. (2008): "El nuevo ámbito subjetivo de aplicación de la Ley de Contratos del Sector Público: luces y sombras", Revista de Administración Pública, 176, 9-54.

GÓMEZ GARCÍA, J.M., ROMÁN ORTEGA, M. \& ROJO GIMÉNEZ, C. (2010): "Las dimensiones de la calidad del empleo en la Economía Social: un análisis de las Sociedades Laborales y de los Centros Especiales de Empleo en Castilla y León", CIRIEC-España, Revista de Economía Pública, Social y Cooperativa, 67, 45-74. 
GUTIÉRREZ, H., NEVADO, Mª.T. \& PACHE, M. (2019): "La contratación pública responsable. Diseño de indicadores de medición", CIRIEC-España, Revista de Economía Pública, Social y Cooperativa, 96, 253-280. DOI: 10.7203/CIRIEC-E.96.12627.

HOOD, C. (2000): "Paradoxes of public-sector managerialism, old public management and public service bargains", International public management journal, 3(1), 1-22. DOI: https://doi.org/10.1016/S1096-7494(00)00032-5.

JIMÉNEZ LARA, A. \& HUETE GARCÍA, A. (2016): Informe Olivenza 2016, sobre la situación de la discapacidad en España (Informe Olivenza), Madrid: Observatorio Estatal de la Discapacidad, disponible en from www.observatoriodeladiscapacidad.info.

KNIGHT, L., HARLAND, C. \& TELGEN, J. (2012): "Public procurement in perspective", Public Procurement, Routledge, 44-52.

LESMES-ZABALEGI, S. \& ÁLVAREZ-DE EULATE BADA, L. (2014): Guía de Contratación Pública Socialmente Responsable, REAS-Euskadi.

LÓPEZ-ARANGUREN, L.M. (2002): "Las Empresas de Inserción en España”, Consejo Económico y Social.

MARCUELLO, C., BELLOSTAS, A., MARCUELLO, C. \& MONEVA, J.M. (2007): "Transparencia y rendición de cuentas en las Empresas de Inserción", CIRIEC-España, Revista de Economía Pública, Social y Cooperativa, 59, 91-122.

MARTíNEZ FONS, D. (2014): "Las restricciones a las cláusulas sociales en la contratación pública impuestas por la libre prestación de servicios. Comentario a la STJUE de 18 de septiembre de 2014, Asunto C-549/13", IUSLabor, núm. 3, pp. 1-9

MCCRUDDEN, C. (2004): "Using public procurement to achieve social outcomes" (Vol. 28, pp. 257267), presentado en el Natural Resources Forum, Wiley Online Library.

MENDOZA JIMÉNEZ, J., ROMÁN CERVANTES, C. \& HERNÁNDEZ LÓPEZ, M. (2018): "Los contratos reservados: una herramienta para el fortalecimiento de las entidades sociales", CIRIECEspaña, Revista Jurídica de Economía Social y Cooperativa, 33, 295-332.

MINISTERIO DE HACIENDA Y FUNCIÓN PÚBLICA (2018): Informe relativo a la contratación pública española 2017, Madrid. Disponible en: shorturl.at/xHIMO.

MONZÓN CAMPOS, J.L. \& CHAVES ÁVILA, R. (2012): "The social economy in the European Union", No. CESE/Contract CES, 18-106. DOI: http://dx.doi.org/10.2864/19534.

MONZÓN CAMPOS, J.L. \& CHAVES ÁVILA, R. (2012): The social economy in the European Union, CIRIEC, Centre international de recherches et d'information sur l'économie publique, sociale et coopérative \& CESE, Comité Économique et Social Européen. 


\section{LA ECONOMIA SOCIAL Y LA CONTRATACION PÚBLICA: LA HERRAMIENTA DE LOS CONTRATOS RESERVADOS}

NAVARRO, A.M. \& CLIMENT, V.C. (2010): "Emprendedurismo y Economía Social como mecanismos de inserción sociolaboral en tiempos de crisis", REVESCO, Revista de Estudios Cooperativos, 100, 43-67. Disponible en: https://www.redalyc.org/pdf/367/36712366002.pdf

NAVARRO, A.M., CLIMENT, V.C. \& PALACIO, J.R.S. (2011): "Emprendimiento social y Empresas de Inserción en España. Aplicación del método Delphi para la determinación del perfil del emprendedor y las empresas sociales creadas por emprendedores", REVESCO, Revista de Estudios Cooperativos, 106, 150. Disponible en: https://www.redalyc.org/pdf/367/36720829007.pdf.

OBSERVATORIO DE LAS OCUPACIONES (2017): Informe del Mercado de Trabajo de las Personas con Discapacidad Estatal 2017, Madrid: Servicio Público de Empleo Estatal. Disponible en: https://www.sepe.es/contenidos/que_es_el_sepe/publicaciones/pdf/pdf_mercado_trabajo/imt2017_datos 2016_estatal_discapacidad.pdf.

ORUEZABALA, G. \& RICO, J.-C. (2012): "The impact of sustainable public procurement on supplier management-The case of French public hospitals", Industrial Marketing Management, 41(4), 573580. DOl: https://doi.org/10.1016/j.indmarman.2012.04.004.

PANIAGUA ZURERA, M. (2013): "Las Empresas de Inserción sociolaboral y las cláusulas sociales en la contratación pública: Dos instrumentos necesarios para la innovación social hacia el desarrollo. Insertion Enterprises and Social Clauses in Public Contracts: Two Necessary Instruments", Social Innovation for Development, 112, 176-212. DOI: https://doi.org/10.5209/revREVE.2013.v112.43066.

PRADINI OLAZÁBAL, J. (2004): Guía para la creación de Empresas de Inserción en Canarias, Tacoronte: Federación Canaria de Desarrollo Rural.

PRADINI, J. \& SÁNCHEZ, E. (2007). "La responsabilidad social en el Tercer Sector", Salud y Drogas, $1(1), 137-151$.

RAYMOND, J. (2008): "Benchmarking in public procurement", Benchmarking: An International Journal, 15(6), 782-793. DOI: https://doi.org/10.1108/14635770810915940.

RETOLAZA ÁVALOS, J.L. \& RAMOS FERNÁNDEZ, M. (2005): "Modelización del costo de las Empresas de Inserción para la administración", CIRIEC-España, Revista de Economía Pública, Social y Cooperativa, 52, 361-385.

RETOLAZA, J.L., SAN-JOSE, L. \& ARAUJO, A. (2014). "La eficiencia como reto de las empresas de inserción". REVESCO, Revista de Estudios Cooperativos, (115), 159-185. DOl:

http://dx.doi.org/10.5209/rev_REVE.2014.v115.45276.

REZZOAGLI, B.A (2016): "Contratación pública para objetivos y resultados: aproximación y discusión teórica", Derecho Público, 37, 1. DOI: http://dx.doi.org/10.15425/redepub.37.2016.01.

RUIZ ROQUEÑI, M., RETOLAZA ÁVALOS, J.L. \& ELORRIAGA, A.M. (2007): "Cláusulas sociales y mercados tutelados: herramientas para la competitividad de las Empresas de Inserción", CIRIECEspaña, Revista de Economía Pública, Social y Cooperativa, 59, 123-151. 
SANMARTíN MORA, M.A. (2014): "La transparencia en la contratación pública, nuevas perspectivas", Contratación administrativa práctica, 129.

TADELIS, S. (2012): "Public procurement design: Lessons from the private sector", International Journal of Industrial Organization, 30(3), 297-302. DOI: doi:10.1016/j.jijndorg.2012.02.002.

THAI, K.V. (2017): Global Public Procurement Theories and Practices, Springer.

UYARRA, E. \& FLANAGAN, K. (2010): "Understanding the innovation impacts of public procurement", European Planning Studies, 18(1), 123-143.

WALKER, H. \& BRAMMER, S. (2009): "Sustainable procurement in the United Kingdom public sector", Supply Chain Management: An International Journal, 14(2), 128-137.

ZÚNIIGA RIAL, G. (2008): "El tratamiento de las cláusulas sociales en la normativa reguladora de la contratación pública: su consideración como criterios de adjudicación de los contratos administrativos", Dereito, 17(2), 65-90. 